\title{
A Multiple Objective Optimisation Model for Building Energy Efficiency Investment Decision th
}

\author{
Esrom Mahlatsi Malatji, Jiangfeng Zhang*, Xiaohua Xia \\ Department of Electrical, Electronic and Computer Engineering \\ University of Pretoria, Pretoria 0002, South Africa \\ Emails: s25449274@tuks.co.za (Esrom Mahlatsi Malatji), zhang@up.ac.za (Jiangfeng \\ Zhang),xxia@postino.up.ac.za (Xiaohua Xia)
}

\begin{abstract}
A multiple objective optimisation model is formulated to help decision makers to make an optimal decision when investing in energy-efficient building retrofitting. The objectives are to maximise the energy savings and minimise the payback period for a given fixed initial investment. The model is formulated as a multiobjective optimisation problem with the net present value (NPV), initial investment, energy target and payback period as constraints and it is solved using genetic algorithms (GAs). The optimal decision is reached by choosing the most optimal actions during energy retrofit in buildings. The model is applied to a case study of a building with 25 facilities that can be retrofitted that illustrates the potential of high energy savings and short payback periods. The sensitivity analysis is also performed by analysing the influence of the auditing error of the facilities, wrongly specified energy savings, the initial investment, changes in interest rate and the changes of electricity prices on the payback period, the maximum energy saved and NPV of the investment. The outcome of this analysis proves that the model is robust.
\end{abstract}

Keywords: Multi-objective optimization, Energy efficient building, Investment, Genetic algorithms, Optimal actions

\footnotetext{
A preliminary version of this paper has been presented at the IFAC Power Plant and Power System Control 2012, Toulose, France, 02-05 September, 2012.

*: Corresponding author, Tel: +27 12 4204335, Fax: +27 123625000 .
} 


\section{Introduction}

The current energy shortage around the world is the reason that energy efficiency is a subject of interest today. The most viable option to counteract this problem is by reducing the current energy consumption. With buildings consuming around $40 \%$ of the worlds total energy [1], it would be beneficial to invest in building energy efficiency retrofit projects. In order to improve the energy efficiency of buildings, inefficient facilities are often replaced by highly advanced energy efficient ones. A whole range of facilities can be retrofitted if there is unlimited funding, although usually this is not the case. Nevertheless the following are some of the retrofit actions that can be taken [2]-[4]:

- Building improvements - Insulating the roof, replacing the single glazing windows with double glazing windows and installing solar shading.

- HVAC system improvements -Installing energy efficient systems with advanced controls.

- Energy efficient lighting - Replacing incandescent lighting by compact fluorescent lighting (CFL) or LED lighting.

- Replacing inefficient equipment - replacing cathode ray tube (CRT) computer monitors with liquid crystal displays (LCD).

- Electromechanical improvements - Installing power factor correcting capacitors to improve the power factor.

The main problem is that most investors are reluctant to invest in energy saving projects such as retrofit projects. This is because such projects are often not able to compete with other investments within the institutions or companies due to unclear benefits. But this is not the case if an investment in energy-efficiency projects is made with the help of decision making tools that can identify large monetary savings. Furthermore, this makes energy efficiency projects competitive with other projects. A decision can be made using the following two approaches [5]-[9]: 
- In the first approach, an energy expert carries out an energy analysis of the building and several alternative scenarios will be developed and evaluated.

- In the second approach decision-making tools such as multi-objective or multi-criteria combined with simulations are applied to assist the decision maker to reach a final decision among a given set of alternative actions..

The multi-criteria technique in the second approach has been used to assist the designers to select the most feasible actions during the initial stages of a renovation project, for energy efficiency improvement of a building [9]. The major setback of this technique is that it is based on predefined sets of actions and scenarios that should be pre-evaluated. In such a case there is no guarantee that the solution reached is the optimal one [7]. Due to the complexity of decisionmaking problems especially ones with multiple objectives, the multi-objective optimisation technique is a suitable candidate to model these problems, because it can explore potentially an unlimited number of alternatives. This technique is used by many researchers mainly with the objective to reduce the cost of the materials and to maximise energy savings. The possibility to use the multiobjective optimisation model to solve the decision problems that consider as many options as possible is widely accepted. [8] Simultaneously minimises the following three objectives: the energy consumption of the building; the initial investment cost; and the annual carbon dioxide emission. [9] Studies a similar problem to balance the energy, environment, financing and social factors. The hybrid decision system is suggested by [10] for sustainable renovation of office buildings and improvements in energy performance, where the decision-maker is facing the challenge of making trade-offs between renovation costs, environmental impacts and improved building quality. The weakness of these studies is that they do not consider the payback period of the investment as one of the objectives. They consider a case of unlimited funding which is not always possible because most of the time there are budget constraints. Another shortfall of these researches is that they do not perform the sensitivity analysis or the robustness test on the model. According to [11] every model has a high 
probability of having uncertainty with regard to some of its parameters. This issue can be addressed by performing the sensitivity analysis or the robustness test. In the study [12] a sensitivity analysis is used before the decision making to validate the robustness of the design decision related to the energy consumption and comfort. The study in [13] makes use of sensitivity analysis to predict the night cooling performance of internal convective heat transfer modelling and the result reveals that some choices of the convectional algorithm may affect the energy and predictions related to the thermal comfort. The study in [14] inspects the robustness of the methodology used to estimate the hourly energy consumption of a given building that considers discrepancies of the parameters within a building. The results show that the methodology can eliminate the errors caused by discrepancies. The research in this paper addresses these shortcomings of the previous researches by constructing a model that will maximise the energy savings and minimise the payback period of the investment, and there will be trade-off between the two if necessary. The contribution of this paper is the addition of the payback period of the investment as an objective, something that has never been considered by previous studies. A sensitivity analysis is performed to illustrate the robustness of the model. The model is constrained by budget, targeted energy savings and acceptable payback periods. This model also considers the time value of money by making use of the net present value (NPV). The research conducted by [8] and [9] present a model that is applicable to the design phase of the building, while the research under this study will present a model that can be used during the operation stage of the building. The model in this paper is applicable to many similar energy retrofit and renovation projects.

Because of the complexity of the multi-objective optimisation models, an easy way to solve them is to use the genetic algorithms (GA). GA can be viewed as a family of computational models that are inspired by evolution. To illustrate the effectiveness of the model obtained in this paper, GA is used to solve the multi-objective optimisation model. Note that other types of popular algorithms, such as particle swarm optimisation, simulated annealing, ant colony, 
and so forth, may also be applied to solve the obtained model.

The paper is organised as follows: In section 2, an optimisation model for investment decision making in buildings energy-efficiency projects is formulated. In section 3 the optimisation model is applied to a case study. The results and simulations of the case study are presented in section 4 . The conclusion is given in the last section.

\section{THE MULTI-OBJECTIVE OPTIMISATION MODEL}

\subsection{Problem Formulation}

The modelling of the energy retrofit problem as a multi-objective optimisation problem is considered in this section. The optimisation model will help the decision-maker to select the most optimal actions to take in order to optimise the objectives. An initial investment will be given and a decision should be made to optimise the following objectives:

- Maximising energy savings and

- Minimising the payback period of the investment. The optimisation model is subjected to NPV, payback period, budget and the energy target constraints.

\subsection{Optimisation model and constraints}

Let $x_{i}$ be a variable representing the quantity of type $i$ facilities to be replaced during the energy retrofits, $1 \leq i \leq n . x_{i}$ must be an integer because the number of facilities cannot be decimals. The optimisation variables of the optimisation model are $(x, T)$ with $x=\left(x_{1}, \ldots, x_{n}\right)$ and $\mathrm{T}$ is the time frame of NPV that will be determined through inequality (4). Since the number of facilities that can be retrofitted is always limited, all the variables must be bounded by the inequality that follows

$$
0 \leq x_{i} \leq l_{i}, i=1, \ldots, n,
$$


where $l_{i}$ is the maximum number of type facilities allowable. The initial investment of the facilities is given by $I_{0}=\sum_{i=1}^{n} x_{i} b_{i}$ and $B=\sum_{t=1}^{T} B_{t}$ is the total annual cost savings of the proposed alternative where $B_{t}=\sum_{i=1}^{n} a_{i} x_{i} c_{i}\left(1+r^{t}\right)$ ) is the cost savings at time instant t. $a_{i}$ is the total average annual energy savings of each facility is given by $a_{i}=E C_{\text {existing }}-E C_{\text {proposed }}$.

The two objectives are to minimise the payback period $\left(f_{1}(x)\right)$ and to maximise the annual energy savings $\left(f_{2}(x)\right)$,

$$
\begin{gathered}
f_{1}(x)=\frac{I_{0}}{B}=\frac{\sum_{i=1}^{n} x_{i} b_{i}}{\sum_{t=1}^{T} \sum_{i=1}^{n} a_{i} x_{i} c_{i}\left(1+r^{t}\right)}, \\
f_{2}(x)=a_{1} x_{i}+a_{2} x_{2}+\ldots+a_{n} x_{n},
\end{gathered}
$$

subject to:

$$
\begin{gathered}
N P V:=\sum_{t=0}^{T} \frac{\left(B_{t}-C_{t}\right)}{\left(1+d_{t}\right)^{t}}-I_{0} \geq 0, \\
0 \leq T \leq \xi \\
b_{1} x_{1}+b_{2} x_{2}+\ldots+b_{n} x_{n} \leq \beta \\
f_{1}(x) \leq 0.1 Z \\
f_{2}(x) \geq 0.1 \alpha
\end{gathered}
$$

where

$a_{i}$ is the average annual energy savings of $i$-th type facility in $\mathrm{kWh}$,

$b_{i}$ is the unit price of the $i$-th type facility,

$c_{i}^{t}$ is the cost of electricity in $\$ / \mathrm{kWh}$ at time t,

$B_{t}$ represents the benefits in year $t$ due to energy savings (\$),

$C_{t}$ represents the operational cost in year $t(\$)$,

$d_{t}$ is the discount rate at time $t$, 
$\xi$ the integer that makes NPV non negative

$\beta$ is the budget of the project $(\$)$,

$\alpha$ is the energy baseline (kWh).

$r^{t}$ is the rate at which electricity price increases

$E C_{\text {existing }}$ is the energy consumption of the of the existing facilities

$E C_{\text {proposed }}$ is the energy consumption of the of the proposed facilities

The objective function $f_{1}(x)$ is the ratio of the initial investment cost by the cost savings as a result of the energy retrofit project. The objective function $f_{2}(x)$ is the sum of products of the quantity of retrofitted facilities and the quantity of energy saved. The two objective functions form an optimisation problem that is subject to constraints of NPV, payback period, budget and the target energy. One of the requirements from investors is that NPV must be greater than zero at the payback period of the investment, hence (4) is the constraint of $f_{1}(x)$. There is no definite way to calculate the exact value of the discount rate $d_{t}$. In most cases the bonds interest of the government is used as a substitute. In South Africa the recommended interests range between 7 to $10 \%$. In this paper the discount rate is taken to be $9 \%$. However under the sensitivity analysis the discount rate varies. The payback period should be as short as possible for the investment to be attractive. The investor will specifies the desired duration to recover the investment; this is shown by (7) which is also the constraint to $f_{1}(x)$. The investor is willing to invest a limited amount of money, $f_{2}(x)$ is constrained by (6). The target is to save a certain percentage of energy relative to the baseline energy. Therefore (8) is also a constraint to $f_{2}(x)$.

\section{GENETIC ALGORITHM WITH A NON-STATIONARY PENALTY FUNCTION}

The problem presented in this paper is a multi-objective problem and there are two methods of solving such a problem. The first one is by combining 
the objectives into one scalar fitness/cost function and the second method is by finding the pareto solutions. The first method makes the multi objective problems easier to be solved by GA [15] and it also gives the decision maker the ability to put more emphasis on certain objections compared to others. The first method is used in this paper. A constant weight must be assigned to each objective depending on its importance in the fitness function. The objective functions in (2) and (3) can be combined to form a single-objective function that will be minimised:

$$
\min \left(\lambda_{1} f_{1}(x)-\lambda_{2} f_{2}(x)\right),
$$

where $\lambda_{1}$ and $\lambda_{2}$ are positive weighting factors satisfying

$$
\lambda_{1}+\lambda_{2}=1 \text {. }
$$

The minimisation problem in (9) is constrained by $(4),(5),(6),(7)$ and (8). GA is initially designed to handle unconstrained optimisation problems, there is a need to use additional tools to keep the solutions within the feasible domain [16]. The penalty function method is the most commonly used method to handle the constraints and it is also used in this paper. The penalty functions method rejects the infeasible solutions by penalising them heavily and reducing their fitness values according to their degrees of constraint violation. Then (9) transforms into a integer programming problem:

$$
\min \left(\lambda_{1} f_{1}(x)-\lambda_{2} f_{2}(x)\right)+p \sum_{r=1}^{N} \max \left(0, h_{k}\right)
$$

where $p$ is the penalty parameter, $h_{k}$ are the constraints and $N$ is the number of constraints. Then $h_{k}$ is as follows: 


$$
h_{k}= \begin{cases}-N P V, & \text { for } \mathrm{k}=1 \\ b_{1} x_{1} \ldots b_{n} x_{n}-\beta, & \text { for } \mathrm{k}=2 \\ \frac{I_{0}}{B}-Z, & \text { for } \mathrm{k}=3 \\ -\left(a_{1} x_{1} \ldots a_{n} x_{n}\right)+\alpha, & \text { for } \mathrm{k}=4\end{cases}
$$

The limitation of the penalty method is that it is very difficult to choose a suitable value of $p$. Research shows that if one makes the value of $p$ bigger more emphasis is placed on convergence to the feasible domain and the GA moves very quickly to the feasible domain which might be far from optimal. Conversely by making the value of $p$ smaller, less emphasis will be placed on feasibility and the chances of converging to the feasible domain become less. To overcome this limitation a non-stationary penalty function is used in this paper. The non-stationary penalty method depends on the generation number as this number increases so does the penalty [17]. In this paper the following are the steps taken to solve integer programming in GA:

Step 0: Generate a random initial population of integer $x(j):=\left(x_{1}^{j} \ldots x_{n}^{j}\right)$ for $j=1 \ldots Q$ where $\mathrm{Q}$ is the population size. The population satisfies the inequalities in (1).

Step 1: Calculate the values of the objective function in (11) for the generated population, i.e., evaluate the fitness of the individuals in the population.

Step 2: Rank the individuals according to their fitness and take the top half as parents. Use the probability distribution functions to assist in selection of the individuals that will mate. Two random vectors are created that will be compared with the probability density function in order to assign indices of the parent individuals that will mate. After the comparison the indices are stored in two different vectors which are parent 1 and parent 2. For example if index 1 of parent 1 is 5 and the index 1 of parent 2 is 21 that means individual 5 and 21 will mate to produce two new offsprings.

Step 3: Mating or crossover every parents to produce new offspring. To ensure that the population integers remain, a single point crossover is employed. Gen- 
erate a random number that assists in selecting the crossover point. The new offsprings are generated by exchanging parts of the parent individuals to each other. This procedure continues for the rest of the population.

Step 4: Genetic mutation. The process of mutation makes the population diverse. The random numbers are generated to select which parts of the individual should be mutated. Also the new individuals generated by mutation are integers.

Step 5: If termination conditions are met then the algorithm terminates, otherwise it returns to Step 2. In the case of a stationary penalty function if the solution is not feasible, the penalty parameter is changed. But in this paper a non-stationary penalty function is applied and if the solution found is deemed final.

This GA method is a modified version of the one formulated by [18]. The similar method to solve integer problem in GA is suggested by [19] and it is applied in the operational planning of district heating and cooling plants. The GA parameters are set as follows:

- The population size is set to be 100 as it provides a high diversity of the solutions and the population size above 100 is found not to give much benefits compared to the former while taking more time to converge.

- The selection rate is set to be $50 \%$ meaning the top performing half of the individuals are selected as parents and this parent selection rate and method shows better performance.

- For mutation rate [18] suggests that it should be between 0.05 to 0.35 usually finds the best minima. In this paper the mutation rate is set to $20 \%$ as it shows much better performance than other values and a single crossover point is employed. 


\section{RESULTS AND DISCUSSION}

To illustrate the efficiency of this optimisation model a simple building is considered as the case study.

\subsection{Case Study}

The building has 25 inefficient facilities that can be replaced by efficient ones. Table 1 gives details of these inefficient facilities, proposed alternatives, and the corresponding investment and saving information. In Table 1, the column 'Maximum possible quantity' refers to the maximum number of alternative facilities which can be used to replace existing inefficient facilities. These maximum quantities are usually determined at the energy audit through various considerations such as whether there is enough space to install these facilities, whether services rendered by these facilities can meet the relevant end user demand, whether it is financially feasible to purchase/install these numbers of facilities, etc. The column 'Unit price' refers to the estimated cost to purchase and install a single facility. The last column 'Unit energy savings' refers to the estimated annual energy savings if an inefficient facility is replaced by a proposed alternative. The cost savings associated with the proposed alternatives are given in Fig. 1. The cost savings are calculated by multiplying the electricity price by estimated unit energy savings, and some of unit cost savings are taken from [20]. The currency of the unit price and cost savings is the US dollar (\$) which is estimated to eight South African Rands (1USD=R8), though it fluctuates everyday. The initial investment is not directly proportional to the energy savings realised by these units. The initial investment includes the labour cost. Currently the average baseline energy of this building is $10655711 \mathrm{kWh}$ per year. The weighting factors $\lambda_{1}$ and $\lambda_{2}$ are changing from 0 to 1 . When the payback period gets a weight of $\lambda_{1}=1$ and the energy savings weight of $\lambda_{2}=0$, the model is designed to select the actions with an emphasis to minimise the payback period. But when the energy savings get a weight of $\lambda_{2}=1$ and the payback period weight of $\lambda_{1}=0$, then the opposite is true. The values of $\lambda_{1}$ and $\lambda_{2}$ resulting in an 
optimal solution should be between 1 and 0 . The optimisation model selects optimal actions (proposed alternatives) in such a way that they satisfy all the constraints given by (4), (5), (6), (7) and (8).

Six cases with different budgets are considered; they all have a budget between $\$ 62500$ up to $\$ 375000$.

- Case A: The initial investment is $\$ 62500$, the desired payback period of the investment is less than three years and the targeted energy to be saved is $10 \%$ or more of the baseline energy.

- Case B: The initial investment is $\$ 125000$, the desired payback period of the investment is less than three years and the targeted energy to be saved is $10 \%$ or more of the baseline energy.

- Case C: The initial investment is $\$ 187500$, the desired payback period of the investment is less than three years and the targeted energy to be saved is $10 \%$ or more of the baseline energy.

- Case D: The initial investment is $\$ 250000$, the desired payback period of the investment is less than three years and the targeted energy to be saved is $10 \%$ or more of the baseline energy.

- Case E: The initial investment is $\$ 312500$, the desired payback period of the investment is less than three years and the targeted energy to be saved is $10 \%$ or more of the baseline energy.

- Case F: The initial investment is $\$ 375000$, the desired payback period of the investment is less than three years and the targeted energy to be saved is $10 \%$ or more of the baseline energy.

The optimisation problem (11) is difficult to solve, so an exhaustive search method is employed to find $\mathrm{T}$ that minimises the objective function. The optimal actions that optimise the objective functions are given in Table 2 and some of the solutions due to these optimal actions are given in Table 
3. For case A there is no solution, as it is impossible to save $10 \%$ of the baseline with only $\$ 62500$ at disposal. In order to achieve the $10 \%$ target an initial investment of more than $\$ 62500$ would be needed. Hence in Table 2 the optimal actions for case A show no solution. Also in any case it is impossible to have a solution with $\lambda_{2}=0$. This means it is impossible to obtain a solution with the emphasis only on minimising the payback period. From the results in the Table 3 it is evident that the NPV is high when the payback period is low. The optimal actions in Table 2 are the number of inefficient facilities being replaced by the proposed alternatives in order to realise the corresponding desired payback period and energy savings. These optimal actions are for the case when $\lambda_{1}$ and $\lambda_{2}$ are both equal to 0.5. To elaborate on how the optimisation model in this paper works and what the optimal actions mean, consider case $\mathrm{F}$ in Table 2. The optimisation model implies that in order to achieve the energy savings and to recoup the initial investment in the payback period given in Table 3, some of the optimal actions to be taken are the following :

- Install 197 motion sensors;

- Replace 529 of downlights type 1 with 529 of $1 \times 13 \mathrm{~W}$ new fitting with energy-saver globe type 1 ;

- Replace 142 of 50W downlights (dimmable) type 1 with 142 of $35 \mathrm{~W}$ new lamp ECG type 1;

- Do not change the chillers;

- Implement the power factor correction;

- Replace 94 electric geysers with 94 heat pumps-9kW;

- Replace 348 highflow shower heads with 348 lowflow shower heads;

- Put 87 heater wraps around the heaters;

- Install 106 heat traps around the pipes; 
- Implement the energy management and control system.

The solutions as a result of these optimal actions are given in Table 3. These solutions are for a scenario when the discount interest rate and electricity prices are taken to be constant. The case where the electricity prices and discount interest rate changes is considered under sensitivity analysis. It should be noted that the number of cases are not restricted to six; actually, an infinite number of cases with different initial investment, desired payback period and the targeted energy savings can be explored. Increasing the initial investment always increases the energy savings, but whether it decreases or increases the payback period depends on the particular case's problem.

\subsection{Sensitivity Analysis}

The optimisation model in this paper may be influenced by external parameters that are discussed below. To investigate the sensitivity of the optimisation model due to these influences, case F with $\lambda_{1}$ and $\lambda_{2}$ chosen to be 0.5 and 0.5 is considered for illustration. The reason for this choice of $\lambda_{1}$ and $\lambda_{2}$ is because this is a case when the payback period and energy savings are equally important. The results of the sensitivity analysis are given in Fig. 2 - Fig. 4. These figures show the influence of the auditing error of the facilities, wrongly specified energy savings, the initial investment, changes in interest rate and the changes of electricity prices on the payback period, the maximum energy saved and NPV of the investment. The base case in these figures refers to the case when there are no external influences.

\subsubsection{Influence of the auditing error of the facilities}

Due to some miscounting of the facilities during the auditing phase of the project because the are too many facilities to count, for example a building can have more than one thousand light fittings to count. According to Fig. 2 - Fig. 4 the energy savings, the payback period and NPV are $2052200 \mathrm{kWh}, 18.8$ months and $\$ 334887.5$ respectively. The percentage energy savings is $19.2 \%$. 
Because of the reduced number of facilities the energy savings are reduced as well at the payback period.

\subsubsection{Influence of electricity prices}

The changes in electricity prices affect the cost savings and hence affect the payback period of the project. This is a scenario that happened in South Africa where the energy regulator approved the utility multi-year tariff increase. The tariffs increase by $24.8 \%$ for the $2010 / 2011,25.8 \%$ for the $2011 / 2012$ and $25.9 \%$ for the 2012/2013 (South Africa Online, 2010). According to Fig. 2 - Fig. 4 the energy savings are $1889900 \mathrm{kWh}$, the payback period is 16.6 months and NPV is $\$ 582275$. The percentage energy savings is $17.7 \%$. The energy savings decrease but the payback period is significantly reduced. The price increase results in large cost savings that lead to shorter payback periods.

\subsubsection{Influence of wrongly specified energy savings}

The energy savings used in this project are obtained from the manufacturers data sheets, it is found that sometimes these savings are over compensated. Fig. 2 - Fig. 4 show the solutions when the energy savings of each facility is lowered by $10 \%$. According to these figures the energy savings are $1900000 \mathrm{kWh}$, the payback period is 20.7 months and NPV is $\$ 271$ 137.5. The percentage energy savings is $17.8 \%$. The decrease in the energy savings of each facility leads to the overall decrease in the energy savings.

\subsubsection{Influence due to the increase in initial investment cost}

Because of fluctuations in economy and other factors the initial investment cost of the facilities can increase. This brings a need to check the influence of this increase on the optimal actions. Fig. 2 - Fig. 4 show the solutions when the initial investment cost is increased by $10 \%$. According to these figures the energy savings are $2173500 \mathrm{kWh}$, the payback period is 26.9 months and NPV is $\$ 120486.25$. The percentage energy savings is $20.4 \%$. The increase in the initial cost of the facilities affect the the cost savings negatively hence the payback period becomes longer. 


\subsubsection{Influence of the changes in interest rates/discount rate}

During bad and good economic times the inflation rate can change, this affects the discount rate and hence affects the time value of money. Fig. 2 - Fig. 4 show the solutions when the interest rate increases by $2 \%$ every year for the duration under study. According to these figures the energy savings are 1900 $000 \mathrm{kWh}$, the payback period is 26.4 months and NPV $\$ 124$ 751.25. The percentage energy savings is $23.6 \%$. Just like the increase in initial investment, the increase in interest rates affects the cost savings negatively hence the payback period becomes longer.

\section{CONCLUSIONS}

The optimisation model is formulated as multi-objective optimisation with constraints. The decisions given by the model are optimal which result in maximum energy savings and low payback periods. The optimisation model is sensitive to the changes in constraints. Any such a change in constraints prominently affects the choice of optimal actions. The model is applied to six different cases and has proved to be efficient. The results show that it is impossible to achieve certain objectives, for instance it is impossible to save $10 \%$ of the baseline energy with the initial investment of only $\$ 62500$. The initial investment directly affects the energy saved and the payback period of the investment. During sensitivity analysis it is realised that the changes in some parameters affects both the energy savings and payback period. The optimisation model is found to be robust as it satisfies the constraints even under the influence of outside parameters. The proposed optimisation model is not restricted to buildings alone, it may also be applied in industries where extra constraints like maintenance costs might be added to make the problem even more complex.

\section{Acknowledgment}

We are grateful to the valuable comments from the anonymous reviewers which assisted in improving the quality of the paper. 


\section{References}

[1] C.A. Balaras, K. Droutsa, E. Dascalaki, S. Kontoyiannidis, Heating energy consumption and resulting environmental impact of European apartment buildings, Energy and Buildings 37 (2005) 429-442.

[2] K. Alanne, Selection of renovation actions using multi-criteria knapsnack model, Automation in Construction 13 (2004) 377-391.

[3] H. Doukas, C. Nychtisandand, J. Psarras, Assessing energy-saving measures in buildings through an intelligent decision support model, Building and Environment 40 (2009) 290-298.

[4] X. Xia, J. Zhang, W. Cass, Energy Management of Commercial BuildingsA Case Study from a POET Perspective of Energy Efficiency, Journal of Energy in Southern Africa 23 (2012) 23-31.

[5] A. Kaklauskas, E.K. Zavadskas, S. Raslanas, Multivariant design and multiple criteria analysis of building refurbishments, Energy and Buildings 37 (2005) 361-372.

[6] L.A. Greening, S. Bernow, Design of coordinated energy and environmental policies: use of multi-criteria decision-making,Energy Policy 32 (2004) 721735.

[7] M.S. Al-Homoud, Optimum thermal design of air-conditioned residential buildings, Building and Environment 32 (2004) 203-210.

[8] D. Kolokotsa, C. Diakaki, E. Grigoroudis, G. Stavrakakis, K. Kalaitzakis, N. Kabelis, A multi-objective decision model for the improvement of energy efficiency in buildings, Energy 35 (2010) 5483-5496.

[9] C. Diakaki, E. Grigoroudis, D. Kolokotsa, Towards a multi-objective optimization approach for improving energy efficiency in buildings, Energy and Buildings 40 (2008) 1747-1754. 
[10] Y. Juan, P. Gao, J. Wang, A hybrid decision support system for sustainable office building renovation and energy performance improvement, Energy and Buildings 42 (2010) 290-297.

[11] A. Saltelli, Sensitivity analysis of model output, Computational Statistics and Data Analysis 15 (1993) 211-238.

[12] S. Attia, E. Gratia, A.D. Herde, J.L.M. Hensen, Simulation-based decision support tool for early stages of zero-energy building design, Energy and Buildings 49 (2012) 2-15.

[13] K. Goethals, H. Breesch, A. Janssens,Sensitivity analysis of predicted night cooling performance to internal convective heat transfer modelling, Energy and Buildings 43 (2011) 2429-2441.

[14] A. Smith, N. Fumo, R. Luck, P.J. Mago, Robustness of a methodology for estimating hourly energy consumption of buildings using monthly utility bills, Energy and Buildings 43 (2011) 779-786.

[15] T. Murata,H. Ishibuchi, Multi-objective genetic algorithms, IEEE International Conference on Evolutionary Computation, Perth, Australia, 29 Nov.-1 Dec., 1995.

[16] O. Yeniay, Penalty function methods for constrained optimization with genetic algorithms, Mathematical and Computational Applications 10 (2005) $45-56$.

[17] J.A. Joines, C.R. Houck, On the use of non-stationary penalty functions to solve non-linear constrained optimization with GAs, Proceedings of the first IEEE International Conference on Evolutionary Computation (2004) $579-584$.

[18] R.L. Haupt, S.E. Haupt, Practical guide to genetic algorithms. second ed., Wiley, New Jersey, 2004. 
[19] M. Sakawa, K. kato, S. Ushiro, M. Inaoka,Sensitivity analysis of predicted night cooling performance to internal convective heat transfer modelling, Energy and Buildings 43 (2011) 2429-2441.

[20] F. Kreith, D.Y. Goswami, Energy management and conservation handbook., CRC Press, New York, 2008. 


\section{List of table captions}

Table 1: Existing facilities(Units), proposed alternative, maximum possible quantity, unit price and unit energy savings

Table 2: Optimal actions

Table 3: Solutions for optimal actions 
Table 1: Existing facilities (units), proposed alternative, maximum possible quantity, unit price and unit energy savings

\begin{tabular}{|c|c|c|c|c|}
\hline Existing facilities (units) & Proposed alternative & $\begin{array}{l}\text { Maximum } \\
\text { possible } \\
\text { quantity }\end{array}$ & $\begin{array}{l}\text { Unit } \\
\text { price } \\
(\$)\end{array}$ & $\begin{array}{l}\text { Unit } \\
\text { energy } \\
\text { savings } \\
(\mathrm{kWh})\end{array}$ \\
\hline No Sensors installed & Motion sensor & 202 & $\$ 196$ & 1141 \\
\hline 50W downlight type 1 & 13W Energy Saver Globe & 537 & $\$ 16.36$ & 208 \\
\hline $\begin{array}{l}\text { 50W Downlight (dimmable) } \\
\text { type } 1\end{array}$ & 35W New Lamp ECG & 145 & $\$ 14.19$ & 102 \\
\hline 18W Recessed Fitting type 1 & 18W Retrofit ECG & 270 & $\$ 11.72$ & 21 \\
\hline 54W Recessed Fitting type 1 & 36W Triphospher tubes & 1271 & $\$ 65.67$ & 232 \\
\hline 2x58W Vapour Proof Fitting & 58W Retrofit ECG & 58 & $\$ 21.25$ & 67 \\
\hline 50W downlight type 2 & 13W Energy Saver Globe & 309 & $\$ 3.66$ & 208 \\
\hline $\begin{array}{l}50 \mathrm{~W} \text { Downlight (dimmable) } \\
\text { type } 2\end{array}$ & 35W New Lamp ECG & 22 & $\$ 9.03$ & 102 \\
\hline $\begin{array}{l}\text { 2x18W Recessed Fitting type } \\
2\end{array}$ & 18W Retrofit ECG & 135 & $\$ 23.44$ & 21 \\
\hline 2x36W Vapour Proof Fitting & 36W Retrofit ECG & 6 & $\$ 27.44$ & 42 \\
\hline 54W Recessed Fitting type 2 & 36W Triphospher tubes & 1187 & $\$ 70.31$ & 232 \\
\hline 58W Open Channel Fitting & 36W Open Channel ECG & 525 & $\$ 36.31$ & 454 \\
\hline 3x36W Old LBR fitting & 2x36W New LBR fitting & 254 & $\$ 71.88$ & 237 \\
\hline Compact Fluorescent & 13W Energy Saver Globe & 40 & $\$ 28.44$ & 3187 \\
\hline High Efficiency Fluorescent & 35W New Lamp ECG & 14 & $\$ 14.19$ & 3080 \\
\hline T12 Lamps & T8 Lamps & 1400 & $\$ 9.64$ & 34 \\
\hline Old Chillers & New Chillers & 4 & $\begin{array}{l}\$ 147 \\
125\end{array}$ & 25392 \\
\hline Poor power factor & Power-factor correction & 1 & $\$ 55000$ & 101567 \\
\hline
\end{tabular}

Continued on next page 
Table 1 - Continued from previous page

\begin{tabular}{|c|c|c|c|c|}
\hline Existing facility (units) & Proposed alternative & $\begin{array}{l}\text { Maximum } \\
\text { possible } \\
\text { quantity }\end{array}$ & $\begin{array}{l}\text { Unit } \\
\text { price } \\
(\$)\end{array}$ & $\begin{array}{l}\text { Unit } \\
\text { energy } \\
\text { savings } \\
(\mathrm{kWh})\end{array}$ \\
\hline Electric geyser & 3kW Heat-pumps & 9 & $\$ 1250$ & 10989 \\
\hline Electric geyser & $22 \mathrm{~kW}$ Heat-pumps & 3 & $\$ 13750$ & 1006 \\
\hline Electric geyser & 9kW Heat-pumps & 94 & $\$ 1250$ & 210989 \\
\hline High flow showerheads & Low-flow showerheads & 360 & $\$ 11.25$ & 278 \\
\hline No heater wrap installed & Heater Wraps & 107 & $\$ 21$ & 273 \\
\hline No thermal traps installed & Thermal traps & 107 & $\$ 8$ & 380 \\
\hline $\begin{array}{l}\text { No Energy Management and } \\
\text { Control Systems installed }\end{array}$ & $\begin{array}{l}\text { Energy Management and } \\
\text { Control Systems }\end{array}$ & 1 & $\$ 300$ & 2790 \\
\hline
\end{tabular}


Table 2: Optimal actions

\begin{tabular}{|c|c|c|c|c|c|c|}
\hline Proposed alternative & Case A & $\begin{array}{l}\text { Case } \\
\text { B }\end{array}$ & $\begin{array}{l}\text { Case } \\
\text { C }\end{array}$ & $\begin{array}{l}\text { Case } \\
\text { D }\end{array}$ & $\begin{array}{l}\text { Case } \\
\text { E }\end{array}$ & $\begin{array}{l}\text { Case } \\
\text { F }\end{array}$ \\
\hline Motion sensor & No solution & 119 & 134 & 70 & 197 & 197 \\
\hline 13W New Energy Saver Globe type 1 & No solution & 536 & 530 & 527 & 528 & 529 \\
\hline 35W New Lamp ECG type 1 & No solution & 102 & 133 & 124 & 133 & 142 \\
\hline 18W Retrofit ECG type 1 & No solution & 17 & 19 & 26 & 22 & 5 \\
\hline 36W New Triphospher tubes & No solution & 25 & 23 & 2 & 158 & 290 \\
\hline 58W Retrofit ECG & No solution & 8 & 7 & 1 & 48 & 51 \\
\hline 13W New Energy Saver Globe type 2 & No solution & 181 & 148 & 133 & 201 & 162 \\
\hline $35 W$ New Lamp ECG type 2 & No solution & 17 & 10 & 22 & 21 & 7 \\
\hline 18W Retrofit ECG type 2 & No solution & 5 & 0 & 34 & 8 & 48 \\
\hline 36W Retrofit ECG & No solution & 0 & 1 & 0 & 2 & 5 \\
\hline 36W Triphospher tubes type 2 & No solution & 33 & 13 & 37 & 297 & 1033 \\
\hline 36W Open Channel ECG & No solution & 472 & 479 & 520 & 508 & 519 \\
\hline 36W New LBR & No solution & 153 & 204 & 251 & 235 & 203 \\
\hline 13W Energy Saver Globe type 3 & No solution & 40 & 38 & 39 & 40 & 40 \\
\hline 35W New Lamp ECG type 3 & No solution & 14 & 14 & 14 & 14 & 14 \\
\hline T8 Lamps & No solution & 101 & 240 & 509 & 940 & 1316 \\
\hline New Chillers & No solution & 0 & 0 & 0 & 0 & 0 \\
\hline Power-factor correction & No solution & 0 & 0 & 1 & 1 & 1 \\
\hline 3kW Heat-pumps & No solution & 0 & 0 & 0 & 0 & 0 \\
\hline $22 \mathrm{~kW}$ Heat-pumps & No solution & 0 & 0 & 0 & 0 & 0 \\
\hline 9kW Heat-pumps & No solution & 35 & 81 & 91 & 94 & 94 \\
\hline Low-flow showerheads & No solution & 315 & 326 & 353 & 317 & 348 \\
\hline Heater Wraps & No solution & 82 & 106 & 102 & 99 & 87 \\
\hline Thermal traps & No solution & 101 & 101 & 103 & 103 & 106 \\
\hline
\end{tabular}

Continued on next page 
Table 2 - Continued from previous page

\begin{tabular}{|l|l|l|l|l|l|l|}
\hline Proposed alternative & Case A & $\begin{array}{l}\text { Case } \\
\text { B }\end{array}$ & $\begin{array}{l}\text { Case } \\
\text { C }\end{array}$ & $\begin{array}{l}\text { Case } \\
\text { D }\end{array}$ & Ease & $\begin{array}{l}\text { Case } \\
\text { F }\end{array}$ \\
\hline $\begin{array}{l}\text { Energy Management and Control Sys- } \\
\text { tems }\end{array}$ & No solution & 0 & 0 & 0 & 0 & 1 \\
\hline
\end{tabular}


Table 3: Solutions for optimal actions

\begin{tabular}{|l|l|l|l|l|l|l|l|}
\hline & $\lambda_{1}$ & $\lambda_{2}$ & $\begin{array}{l}\text { Payback } \\
\text { period } \\
(\text { Month })\end{array}$ & $\begin{array}{l}\text { Energy } \\
\text { savings } \\
(\mathbf{k W h})\end{array}$ & $\begin{array}{l}\text { Percentage } \\
\text { saved }\end{array}$ & NPV (\$) & T \\
\hline Case A & 0.5 & 0.5 & No solution & No solution & No solution & No solution & - \\
\hline Case B & 0.5 & 0.5 & 17.0 & 1269000 & $11.9 \%$ & $\$ 29511.25$ & 2 \\
\hline Case C & 0.5 & 0.5 & 17.6 & 1803900 & $16.9 \%$ & $\$ 225662.5$ & 4 \\
\hline Case D & 0.5 & 0.5 & 20.3 & 2005500 & $18.8 \%$ & $\$ 76253.75$ & 2 \\
\hline Case E & 0.5 & 0.5 & 17.7 & 2280000 & $21.4 \%$ & $\$ 59375$ & 2 \\
\hline Case F & 0.5 & 0.5 & 20.3 & 2490000 & $23.4 \%$ & $\$ 186250$ & 3 \\
\hline
\end{tabular}




\section{List of figure captions}

Figure 1: Unit cost savings realized by proposed alternatives $(\$)$

Figure 2: Sensitivity of the energy savings (kWh)

Figure 3: Sensitivity of the payback period(Month) Figure 4: Sensitivity of the $\operatorname{NPV}(\$)$ 


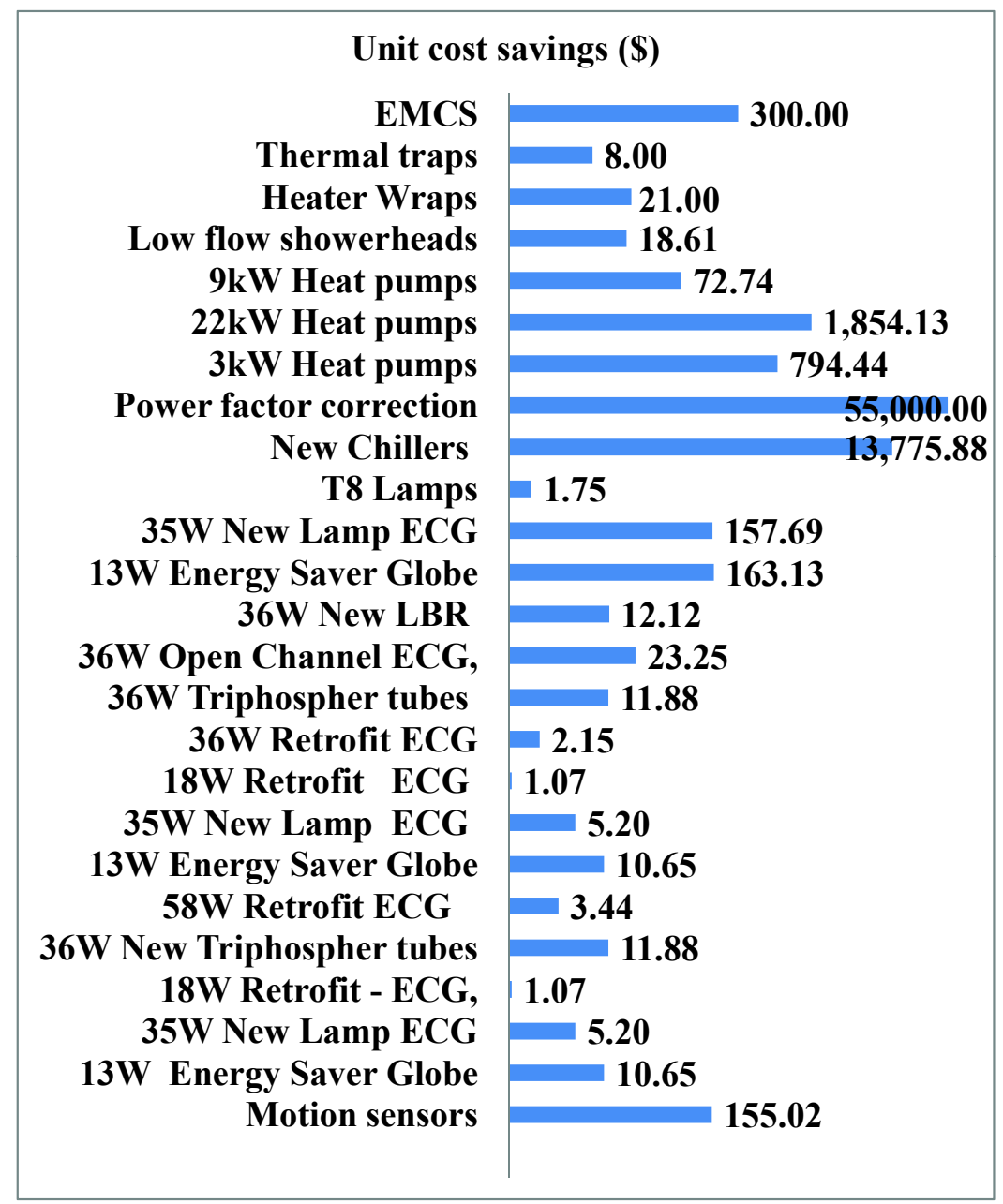

Figure 1: Unit cost savings realized by proposed alternatives (\$) 


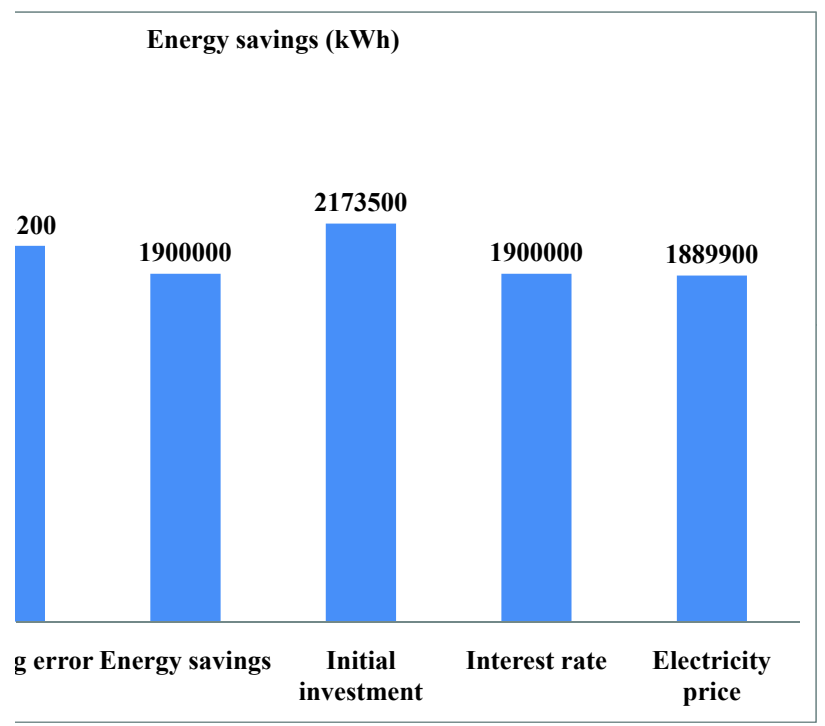

Figure 2: Sensitivity of the energy savings (kWh) 


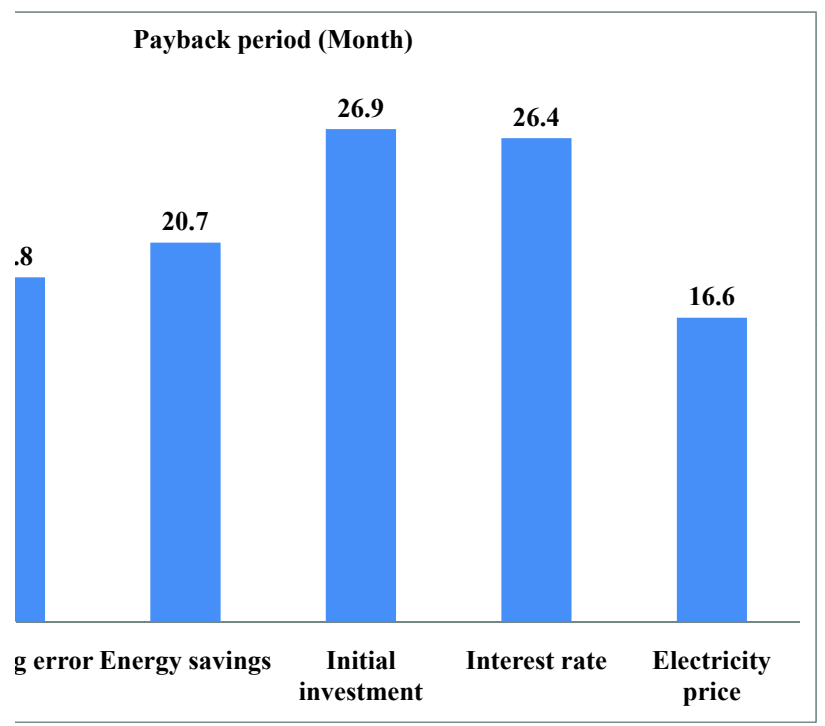

Figure 3: Sensitivity of the payback period(Month) 


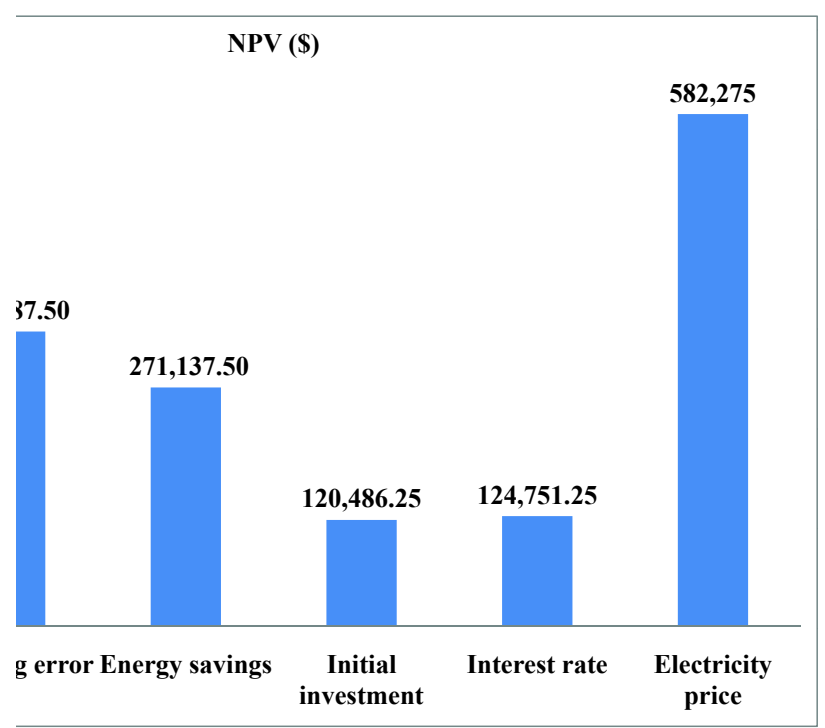

Figure 4: Sensitivity of the NPV(\$) 